Journal Of Al Azhar University Engineering Sector

Vol. 13, No. 46, January, 2018, 14-19

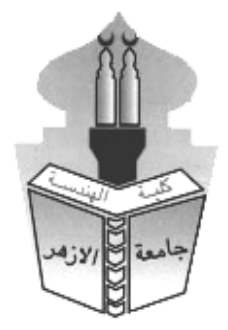

\title{
FACTORS AFFECTING CONSTRUCTION PLANNING
}

\author{
Eman Fathi El-Din Ahmed, Hossam Eldin Hosni and Ahmed El Yamany \\ Department Construction Engineering, Zagazig University, Egypt
}

\begin{abstract}
Construction planning CP can be considered as one of the most important phases in construction projects. This research aims to find the most important Factors affecting Construction Planning (CP). Those factors identified using the following two steps. First, collecting factors affecting CP through a comprehensive literature review. Second, identifying the most important planning factors using Delphi technique. This research helps practitioner engineers to create successful plans by focusing on specific factors affecting project planning.
\end{abstract}

Keywords: Planning, Preconstruction project, Poor planning, successful plan, Delphi, Factors, Planning engineer.

\section{INTRODUCTION}

A growing challenge for the construction industry stakeholders is to have a successful completion of the project within time and budget. A recent study of Project Management South Africa (PMSA) revealed that out of 300 global megaprojects with budgets of over $\$ 1$ billion, $65 \%$ failed to meet the objectives established at final investment stage. Further, this study also highlighted only $25 \%$ of large construction project finished on time within budget. Most of the factors that always affect the project profitability and successful completion of the project can be controlled through construction planning $(\mathrm{CP})$ effort that usually require $2 \%$ to $5 \%$ of the total installed cost of a project but also depends on type and complexity of the project. (Abbas and Farooqui, 2016).

\section{PROBLEM STATEMENT AND RESEARCH OBJECTIVE}

Searching the literature, there are little researches focuses on factors affecting $\mathrm{CP}$. therefore, the objectives of this research are:

I) Collecting factors expected to affect the $\mathrm{CP}$ from previous studies.

II) Identifying the most important factors affecting $\mathrm{CP}$.

\section{METHODOLOGY}

The methodology of this research can be summarized as follows:

- Surveying the literature to identifying factors affecting CP.

- Building a list of collected factors.

- Categorizing CP factors in the list of collected factors.

- Using the Delphi technique to build a short list of the most important factors.

\section{LITERATURE REVIEW}

Preconstruction planning is a comprehensive set of procedures initiated after contract award and prior to construction execution. Preconstruction planning has also been referred to pre-job planning, pre-planning, or execution planning. The Plumbing-Heating-Cooling Contractors 
(PHCC) National Association lists the benefits of preconstruction planning as greater project control, increased project organization, better worker productivity, improved safety record, and increased project profitability. The planning process for most capital projects is similar, but needs to be adapted to the conditions that are unique to a particular project and business circumstance (Hanna and Skiffington, 2010).

Hamilton and Gibson state that the construction industry recognizes that the effort expended in preplanning results in more successful projects (George et al., 2008). The lack of preconstruction planning is surely the greatest failure of contractors in the entire construction industry. The previous studies concluded that poor planning is one of major reasons of project failure (Son and Rojas 2010).

Because of poor scope definition, final project costs tend to be higher because of changes that interrupt project rhythm, cause rework, increase project time, and lower the productivity as well as the morale of the field work force (Gibson et al, 2006).

Hanna and Skiffington (2010) conduct a research about PCP. The research concluded that projects which are well planned, perform superior relative to those project that were poorly planned in the areas of profit, general contractor satisfaction, budgeted cost, budgeted work hours, quality, relationship with the owner, relationship with the general contractor, and team member communication. The research presented a process to guarantee successful $\mathrm{CP}$. The research claimed that projects used a planning process similar to that of the research, achieved an average profit margin of $23 \%$, whereas projects that were poorly planned experienced an average profit margin of $3 \%$.

The current research identified sixty-six factors affecting $\mathrm{CP}$ from literature review as shown in Table 1.

Table 1. Construction Planning Factors collected from previous studies.

\begin{tabular}{|c|c|c|c|c|c|c|c|c|c|c|c|}
\hline Categories & 4 & 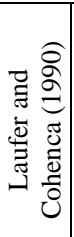 & 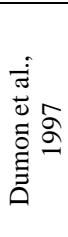 & 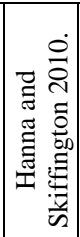 & 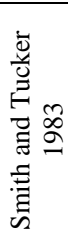 & 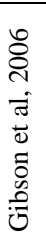 & 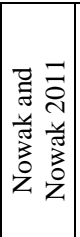 & 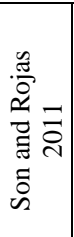 & 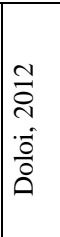 & 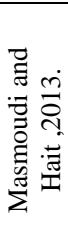 & 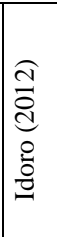 \\
\hline \multirow{3}{*}{ Company } & Conduct a formal kickoff meeting and site visit. & & & $\sqrt{ }$ & & & & & & & \\
\hline & Select team members. & & & $\sqrt{ }$ & & & & & & & \\
\hline & Review lessons learned. & & & $\sqrt{ }$ & & & & & & & \\
\hline \multirow{10}{*}{ Project } & Knowledge of project requirement. & & & & & & & & & & \\
\hline & Past experience from last similar projects. & $\sqrt{ }$ & & & & & $\sqrt{ }$ & & & & \\
\hline & Review general and supplementary conditions. & & & $\sqrt{ }$ & & & & & & & \\
\hline & Identify special requirements. & & & $\sqrt{ }$ & & & & & & & \\
\hline & Create list of unknown information. & & & $\sqrt{ }$ & & & & & & & \\
\hline & Review the signed contract. & & & $\sqrt{ }$ & & & & & & & \\
\hline & Review specifications for quality requirements. & & & $\sqrt{ }$ & & & & & & & \\
\hline & Financial analysis. & & & & & & $\sqrt{ }$ & & & & \\
\hline & Project scope definition. & & $\sqrt{ }$ & . & $\sqrt{ }$ & & & & $\sqrt{ }$ & & \\
\hline & Define project objectives. & & & & & & & & & & $\sqrt{ }$ \\
\hline \multirow{15}{*}{$\begin{array}{l}\text { Engineer } \\
\text { Staff }\end{array}$} & Accurate work flow planning. & & & & & & & & $\sqrt{ }$ & & \\
\hline & Identify and price substitute materials and equipment. & & & $\sqrt{ }$ & & & & & & & \\
\hline & Submit substitution request to owner/CM/GC. & & & $\sqrt{ }$ & & & & & & & \\
\hline & Discuss alternative duct routes. & & & $\sqrt{ }$ & & & & & & & \\
\hline & Identify potential cost savings. & & & $\sqrt{ }$ & & & & & & & \\
\hline & Review subcontractor bids, qualifications, and work load. & & & $\sqrt{ }$ & & & & & & & \\
\hline & Review scope of work with subcontractors. & & & $\sqrt{ }$ & & & & & & & \\
\hline & Write contracts for selected subcontractors. & & & $\sqrt{ }$ & & & & & & & \\
\hline & Obtain and review owner/CM/GC schedule. & & & $\sqrt{ }$ & & & & & & & \\
\hline & Identify mobilization /demobilization dates. & & & $\sqrt{ }$ & & & & & & & \\
\hline & Identify and establish delivery dates for long lead time items. & & & $\sqrt{ }$ & & & & & & & \\
\hline & Identify construction equipment delivery dates. & & & $\sqrt{ }$ & & & & & & & \\
\hline & Identify work by others directly impacts project activities. & & & $\sqrt{ }$ & & & & & & & \\
\hline & Coordinate schedule with other subcontractors. & & & $\sqrt{ }$ & & & & & & & \\
\hline & Establish project subcontractor start/finish date. & & & $\sqrt{ }$ & & & & & & & \\
\hline
\end{tabular}




\begin{tabular}{|c|c|c|c|c|c|c|c|c|c|c|c|}
\hline Categories & $\mathrm{Y}^{-3}$ & 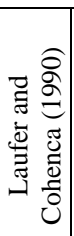 & 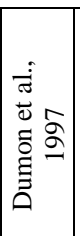 & 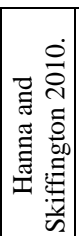 & 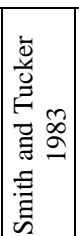 & 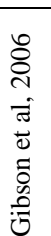 & 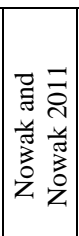 & 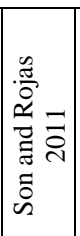 & 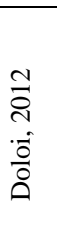 & 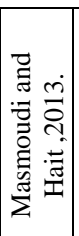 & 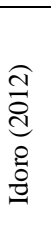 \\
\hline & Review specifications for quality requirements. & & & $\sqrt{ }$ & & & & & & & \\
\hline & Inform workers of required quality standards. & & & $\sqrt{ }$ & & & & & & & \\
\hline & Review safety lessons learned from other jobs. & & & $\sqrt{ }$ & & & & & & & \\
\hline & Review safety and OSHA requirements. & & & $\sqrt{ }$ & & & & & & & \\
\hline & Search the site for hazards before construction begins. & & & $\sqrt{ }$ & & & & & & & \\
\hline & Inform workers of required safety standards. & & & $\sqrt{ }$ & & & & & & & \\
\hline & Determine long lead-time items. & & & $\sqrt{ }$ & & & & & & & \\
\hline & Contract material and equipment suppliers. & & & $\sqrt{ }$ & & & & & & & \\
\hline & Order/prepare shop drawings for long lead-time items. & & & $\sqrt{ }$ & & & & & & & \\
\hline & Develop purchase orders for materials and equipment. & & & $\sqrt{ }$ & & & & & & & \\
\hline & Review estimated work hours. & & & $\sqrt{ }$ & & & & & & & \\
\hline & Develop a sequence of work and create a schedule of values. & & & $\sqrt{ }$ & & & & & & & \\
\hline & Prepare a manpower loading chart. & & & $\sqrt{ }$ & & & & & & & \\
\hline & Develop CAD drawings to identify conflicts & & & $\sqrt{ }$ & & & & & & & \\
\hline & Identify materials and systems that can be prefabricated. & & & $\sqrt{ }$ & & & & & & & \\
\hline & Identify shop fabrication requirements and their schedule. & & & $\sqrt{ }$ & & & & & & & \\
\hline & Schedule delivery of prefabricated materials. & & & $\sqrt{ }$ & & & & & & & \\
\hline & Identify field reporting procedures and create project file. & & & $\sqrt{ }$ & & & & & & & \\
\hline & Review change order procedures. & & & $\sqrt{ }$ & & & & & & & \\
\hline & Review billing procedures and prepare a billing schedule. & & & $\sqrt{ }$ & & & & & & & \\
\hline & Receive storage approval from owner/CM/GC. & & & $\sqrt{ }$ & & & & & & & \\
\hline & Consideration of buildability & & & & & & & & $\sqrt{ }$ & & \\
\hline & Agreement on appropriate project budget and delivery time. & & & & & & & & $\sqrt{ }$ & & \\
\hline & Clear process of project control. & & & & & & & & $\sqrt{ }$ & & \\
\hline & Clear change request protocol. & & & & & & & & $\sqrt{ }$ & & \\
\hline & Monitoring and status reporting protocols. & & & & & & & & $\sqrt{ }$ & & \\
\hline & Clear understanding of the project scope. & & & & & & & & $\sqrt{ }$ & & \\
\hline & Understanding the design. & & & & & & & & $\sqrt{ }$ & & \\
\hline & Construction methods and techniques. & & & & & & & & $\sqrt{ }$ & & \\
\hline & Complexity of on-site construction activities. & & & & & & & & $\sqrt{ }$ & & \\
\hline & Experience and intuition of the project team members. & & & & & & $\sqrt{ }$ & & $\sqrt{ }$ & & \\
\hline \multirow{7}{*}{$\begin{array}{l}\text { Site } \\
\text { Conditions }\end{array}$} & Receive storage approval from owner/CM/GC. & & & $\sqrt{ }$ & & & & & & & \\
\hline & \begin{tabular}{|l} 
Discuss storage, site layout, and handling of materials. \\
\end{tabular} & & & $\sqrt{ }$ & & & & & & & \\
\hline & $\begin{array}{l}\text { Establish procedures for receiving, storing, and handling } \\
\text { material. }\end{array}$ & & & $\sqrt{ }$ & & & & & & & \\
\hline & Identify construction equipment required. & & & $\sqrt{ }$ & & & & & & & \\
\hline & Resource availability. & & & & & & & & & $\sqrt{ }$ & $\sqrt{ }$ \\
\hline & Late material delivery. & & & & & & & $\sqrt{ }$ & & & \\
\hline & Bad weather conditions. & $\sqrt{ }$ & & & & & & $\sqrt{ }$ & & & \\
\hline
\end{tabular}

\section{DATA COLLECTION AND ANALYSIS}

The Delphi survey technique developed in the 1950s by two research scientists working at The Rand Corporation, Olaf Helmer and Norman Dalkey (Ludwig, 1994; Custer et al, 1999). The Delphi technique designed as a group communication process that aims at conducting detailed examinations and discussions of a specific issue for the purpose of goal setting, policy investigation, or predicting the occurrence of future events (Turoff and Hiltz, 1996).

The surveyed panel consists of 29 experienced engineers. The classification of the surveyed panel experiences is shown in Table 2.

Table 2. Classification of the surveyed experts based on their experience

\begin{tabular}{|c|c|c|c|c|c|}
\hline Years of experience & $\begin{array}{l}\text { Project } \\
\text { Managers }\end{array}$ & $\begin{array}{l}\text { Planning } \\
\text { Engineer }\end{array}$ & Site Engineer & Total & \% \\
\hline $\mathbf{1 0}$ years & - & 5 & - & 5 & 17.2 \\
\hline$\geq \mathbf{1 0}$ years and $>\mathbf{1 5}$ & 6 & 9 & 3 & 18 & 62.1 \\
\hline$\geq \mathbf{1 5}$ years & 3 & 3 & - & 6 & 20.7 \\
\hline
\end{tabular}


Questionnaires were sent by mail to the expert panel in 3 consecutive rounds. The first round consists of sixty-six factors listed in Table 1. The surveved experts were asked to: Rate each factor using a five-point Likert scale (1=Extremely Ineffective, 2=Moderately Ineffective, $3=$ Neutral, 4=Moderately Effective, 5 = Extremely Effective)

1. Add factors other than listed, if any.

2. Modify factors, if any.

3. Add suggestions, if any.

To evaluate mean of different factors, the weighted arithmetic mean is utilized as shown in Equation 1, is used:

$$
\text { Mean }=\sum_{i=1}^{n} W i X i \frac{\mathrm{m}}{\sum_{i=1}^{n} X i}
$$

Where:

$\mathrm{X}_{\mathrm{i}}$ : indicate responses (with non-negative value).

$\mathrm{W}_{\mathrm{i}}$ : indicate weight (with non-negative value).

$\mathrm{n}$ : is number of responses.

The first round eliminated 43 factors out of 66 and add one new factor "Resource capacity". The result of the second round eliminated 15 factors from 24 factors. The consensus was reached in the third round as the experts sent back the same 9 factors without eliminating or adding any as shown in Table 3.

Table 3. CP Factors after the Third round

\begin{tabular}{|l|l|c|}
\hline \multirow{2}{*}{ Category } & Factor & $\begin{array}{c}\text { Delphi } \\
\text { score Mean }\end{array}$ \\
\hline \multirow{2}{*}{ Company (C1) } & Resource capacity. & 4.00 \\
\cline { 2 - 3 } & Select team members. & 3.83 \\
\hline \multirow{3}{*}{ Project (C2) } & Project scope definition. & 4.00 \\
\cline { 2 - 3 } & Past experience from last similar projects. & 3.67 \\
\cline { 2 - 3 } & Financial analysis. & 3.67 \\
\hline \multirow{2}{*}{ Engineer Staff (C3) } & Accurate work flow planning. & 3.83 \\
\cline { 2 - 3 } & Experience and intuition of the project team members. & 4.17 \\
\hline \multirow{2}{*}{ Site conditions (C4) } & Resource availability. & 3.67 \\
\cline { 2 - 3 } & Late material delivery. & 3.83
\end{tabular}

As shown in Table 3, the mean value ranging between 3.67 and 4.17. In company category, "resource capacity" is the most important factor with mean score 4.00. In proiect category, "proiect scope definition" is the most important factor in project category with mean score 4.00. In Engineering staff category, "experience and intuition of the proiect team members", is the most important factor with mean score 4.17. In site conditions category, "late material delivery" is the most important factor with mean score 3.83. All Delphi score values are summarized as shown in Fig. 1.

All those factors are the most important factors affecting CP. For example, resource capacity is important because the proiect performance depends widely on it. The relationship between resource capacity is proportional whenever percentage of resource capacity in company increased the performance of project increased. Also, selecting team member like project manager, planning engineer, site engineers, labors ..... ets, is important because deficit of members may cause cost or schedule delay.

On the other hand, proiect scope definition explains drawing, specifications and all information about the project, it helps the engineer to understand and manage the proiect and make effective work breakdown structure which is considered to be one of the most important factors affecting CP. Also, knowledge about previous similar proiects helps engineer to avoid mistakes which happened before. While, engineer experience is also very important factor 
whereas the vears of experience increased, the ability of avoiding repetitive problems increased and makes quick decision in problems.

Undoubtedly, resource availability and late material delivery affect the efficiency of $\mathrm{CP}$ since if not taken in account those factors, it will cause cost or schedule delay.

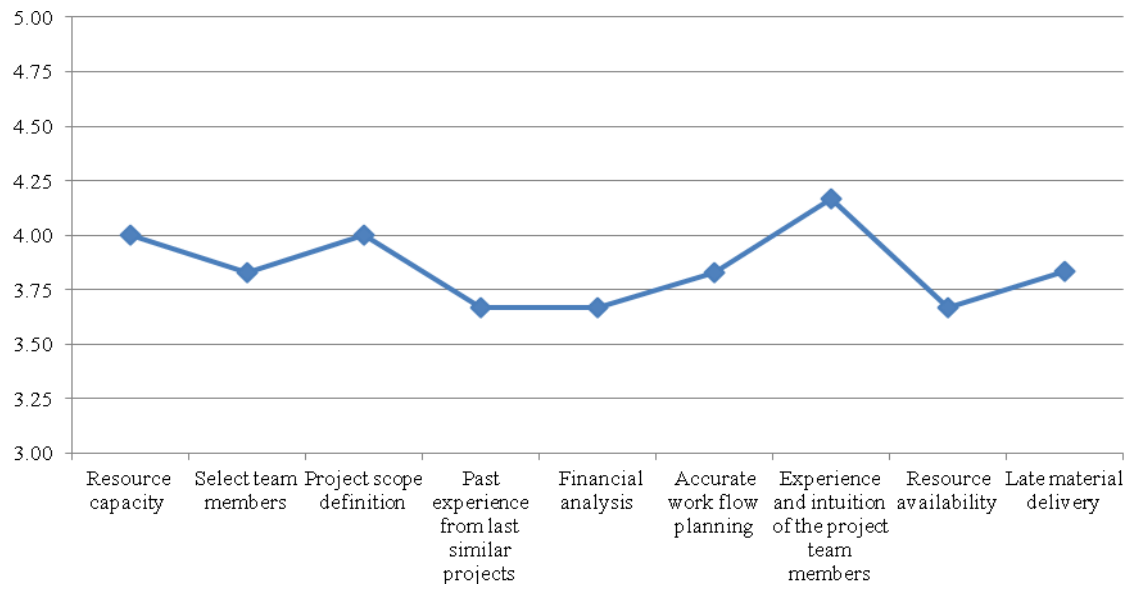

Fig. 1. Results of Round three showing the most important factors affecting (PCP)

\section{CONCLUSIONS AND RECOMMENDATION:}

The aim of this research was to utilize the most important factors affecting CP. Sixty-six factors were collected from literature review. Those 66 factors minimized to 9 factors using Delphi technique. The analysis showed that "Resource capacity" is the most important factor in company category while "Project scope definition" is the most important factor in project category. On other hand, "Experience and intuition of the project team members" is the most important factor in engineering staff category. Finally, "Late material delivery" is the most important factor in engineering staff category. Research results recommend conducting a classification for construction proiects according to their type, cost or work area and increasing number of respondents to get more accurate results.

\section{REFERENCE}

1. Abbas, A., Din, Z. U., \& Farooqui, R. (2016). "Achieving Greater Proiect Success \& Profitability through Pre-construction Planning: A Case-based Study". Procedia Engineering, 145, 804-811.

2. Custer, R. L., Scarcella, J. A., \& Stewart, B. R. (1999). The Modified Delphi Technique-A Rotational Modification. Journal of vocational and technical education, 15(2), 50-58.

3. Doloi, H. (2012). Cost overruns and failure in project management: Understanding the roles of key stakeholders in construction projects. Journal of construction engineering and management, 139(3), 267-279.

4. George, R., Bell, L. C., \& Edward Back, W. (2008). "Critical activities in the front-end planning process". Journal of Management in Engineering, 24(2), 66-74.

5. Gibson Jr, G. E., Wang, Y. R., Cho, C. S., \& Pappas, M. P. (2006). "What is preproject planning, anyway?". Journal of Management in Engineering, 22(1), 35-42.

6. Hanna, A. S., \& Skiffington, M. A. (2010). "Effect of preconstruction planning effort on sheet metal project performance". Journal of Construction Engineering and Management, 136(2), 235-241.

7. Idoro, G. I. (2012). Comparing the planning and performance of direct labour and designbid-build construction projects in Nigeria. Journal of Civil Engineering and Management, 18(2), 184-196. 
8. Laufer, A., \& Cohenca, D. (1990). Factors affecting construction-planning outcomes. Journal of Construction Engineering and Management, 116(1),

9. Ludwig, B. G. (1994). Internationalizing Extension: An exploration of the characteristics evident in a state university Extension system that achieves internationalization (Doctoral dissertation, The Ohio State University).

10. Masmoudi, M., \& HaïT, A., (2013). "Project scheduling under uncertainty using fuzzy modelling and solving techniques,". Engineering Applications of Artificial Intelligence, 26(1), 135-149.

11. Nowak, B., \& Nowak, M., (2011). "Multi-criteria Decision Aiding in Project Planning Using Decision Trees and Simulation,". Multiple Criteria Decision Making, 10-11, 163187.

12. Smith, M. A., \& Tucker, R. L. (1983). An assessment of the potential problems occurring in the engineering phase of an industrial project. Construction Industry Institute, University of Texas at Austin.

13. Son, J., \& Rojas, E. M. (2010). Impact of optimism bias regarding organizational dynamics on project planning and control. Journal of construction engineering and management, 137(2), 147-157.

14. Turoff, M., \& Hiltz, S. R. (1996). Computer based Delphi processes. Gazing into the oracle: The Delphi method and its application to social policy and public health, 56-85. "https://web.njit.edu/ turoff/Papers/delphi3.html last seen 11/4/2017". 